\title{
Suitability of three common reference genes for quantitative real-time PCR in honey bees
}

\author{
Tina Reim ${ }^{1}$, Markus Thamm ${ }^{1}$, Daniel Rolke ${ }^{1}$, Wolfgang Blenau ${ }^{2}$, \\ Ricarda SCHEINER ${ }^{1}$

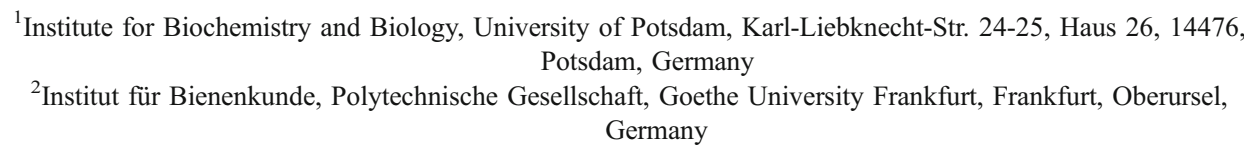

Received 17 July 2012 - Revised 22 October 2012 - Accepted 9 November 2012

\begin{abstract}
Honey bees are important model organisms for neurobiology, because they display a large array of behaviors. To link behavior with individual gene function, quantitative polymerase chain reaction is frequently used. Comparing gene expression of different individuals requires data normalization using adequate reference genes. These should ideally be expressed stably throughout lifetime. Unfortunately, this is frequently not the case. We studied how well three commonly used reference genes are suited for this purpose and measured gene expression in the brains of honey bees differing in age and social role. Although rpl32 is used most frequently, it only remains stable in expression between newly emerged bees, nurse-aged bees, and pollen foragers but shows a peak at the age of 12 days. The genes gapdh and efl $\alpha-f 1$, in contrast, are expressed stably in the brain throughout all age groups except newly emerged bees. According to stability software, gapdh was expressed most stably, followed by $r p l 32$ and efl $\alpha-f 1$.
\end{abstract}

gene expression / quantitative PCR / reference gene / stability program / Apis mellifera

\section{INTRODUCTION}

The quantification of gene transcript is frequently used in molecular behavioral biology. Quantitative real-time polymerase chain reaction (qPCR) is the technique of choice to analyze changes in the amount of gene-specific mRNA. It is highly sensitive and allows quantification of rare transcripts and small changes in gene expression (Pfaffl 2001; Bustin and Nolan 2004).

Comparing samples requires normalization to compensate for differences in the amount of biological material and RNA content in the tested samples. Normalization to an internal reference

Corresponding author: R. Scheiner, ricarda.scheiner-pietsch@uni-potsdam.de Manuscript editor: Stan Schneider gene is the most popular strategy. However, finding appropriate reference genes for data normalization is one of the most challenging problems today (Kubista et al. 2006). The ideal reference gene should be expressed at a constant level among different tissues of an organism, at all stages of development, and should be unaffected by the experimental treatment (Bustin 2000). But many genes are regulated under certain conditions, and there is no universal reference gene with a constant expression in all tissues (Bustin 2000; Suzuki et al. 2000; Huggett et al. 2005). Therefore, it is necessary to investigate and validate different reference genes under the same experimental conditions to use them for normalizing gene expression.

Studies for the validation of insect reference genes were made in various insect species, for 
example, in Drosophila melanogaster (Ling and Salvaterra 2011; Ponton et al. 2011), Bombus terrestris and Bombus lucorum (Hornáková et al. 2010), Tribolium castaneaum (Lord et al. 2010), Rhodnius prolixus (Majerowicz et al. 2011), Cimex lectularius (Mamidala et al. 2011), Lucilia cuprina (Bagnall and Kotze 2010), and locusts like Schistocerca gregaria (Van Hiel et al. 2009), and Chortoicetes terminifera (Chapuis et al. 2011). In the honey bee $A$. mellifera, a model organism for studies on social behavior, reference genes were investigated in-depth only in larval and pupal stages (Lourenco et al. 2008) and in the brains of young honey bee workers after a bacterial challenge (Scharlaken et al. 2008).

We tested the suitability of the three commonly used insect reference genes (1) elongation factor 1 alpha-fl (efl $\alpha-f 1)$, one of two efl $\alpha$ genes in the honey bee (Walldorf and Hovemann 1990; Danforth and Shuqing 1998), (2) glyceraldehydes-3-phosphate dehydrogenase (gapdh), and (3) ribosomal protein L32 ( $r p l 32$, former $r p 49$ ) for qPCR studies in honey bee workers. All three genes are involved in different pathways and belong to different functional classes.

We measured changes in the brain expression of these genes during adult development of honey bees. The suitability of the three genes as references in qPCR studies was subsequently analyzed using software packages Bestkeeper, Genorm $^{\text {PLUS }}$, and NormFinder. These three programs are well established, most commonly used and freely available.

\section{MATERIALS AND METHODS}

\subsection{Bees}

Bees were kept in a commercial hive on the campus of the university in Potsdam. A comb with capped brood shortly before emergence was removed from the hive and placed in a humidified incubator at $34{ }^{\circ} \mathrm{C}$ till the adult bees emerged from their brood cells. Three to $5 \mathrm{~h}$ after emergence, the bees were paint-marked on their thoraces to enable the experimenter to distinguish between the different age groups. All marked bees were restored to their colony of origin. At specific time points after emergence, ten bees per group (biological replicates) were collected directly from the colony into small glass tubes between 9 and $10 \mathrm{AM}$. Pollen foragers were collected at the hive entrance and identified by loads of pollen attached to their legs. Returning bees without filled pollen baskets, which displayed an extended abdomen, were regarded as nectar foragers. All bees were collected in May and June.

\subsection{Sample preparation and storage}

The experimental procedures were performed according to the MIQE guidelines (Bustin et al. 2009). The bees were individually placed in metal harnesses with a strip of tape fixed between the head and thorax and a second strip fixed over the abdomen to prevent movement and stinging. The head was fixed at the first strip with beeswax. The brain was dissected in cold bee saline $(\mathrm{NaCl} 270 \mathrm{mM}, \mathrm{KCl}$ $3.2 \mathrm{mM}, \mathrm{MgCl}_{2} 10 \mathrm{mM}, \mathrm{CaCl}_{2} 1.2 \mathrm{mM}, 3-(N-$ morpholino) propanesulfonic acid $10 \mathrm{mM}, \mathrm{pH}$ 7.3). The hypopharyngeal glands, the salivary glands, the trachea on top of the brain, and the retinal pigment were removed during the dissection of each brain. Then, the whole brain was immediately frozen in liquid nitrogen and stored at $-80{ }^{\circ} \mathrm{C}$ until RNA extraction.

\subsection{RNA extraction and cDNA synthesis}

The frozen brains were homogenized in the reaction tube with a pestle $\left(1.5 \mathrm{~cm}^{3}\right)$, and total RNA was extracted using the RNeasy Mini Kit (Qiagen, Hilden, Germany) according to the manufacturer's instructions. DNase treatment was not performed, because of the intron-spanning primers used. For quantification, RNA concentration was measured at $260 \mathrm{~nm}$ using a GeneQuant 1300 spectrophotometer (GE Healthcare UK Limited). Purity of total RNA was determined as the 260/280 ratio with values ranging between 1.8 and 2 . The integrity of total RNA was proved once by electrophoresis on a $1 \%(w / v)$ agarose gel to demonstrate the success of the extraction procedure. Because of 
the "hidden break" in the 28S rRNA in insects, samples were considered intact when the 18S rRNA was visible as a clear band (Mustard et al. 2003; Winnebeck et al. 2010).

First-strand cDNA synthesis was carried out in duplicate (technical replicate) using the SuperScript ${ }^{\mathrm{TM}}$ III First-Strand Synthesis SuperMix for qRT-PCR (Life Technologies GmbH, Darmstadt, Germany). About $500 \mathrm{ng}$ of total RNA, $10 \mu \mathrm{L} 2 \times$ RT reaction mix, and $2 \mu \mathrm{L}$ enzyme mix were gently mixed in a total volume of $20 \mu \mathrm{L}$ and incubated at $25^{\circ} \mathrm{C}$ for $10 \mathrm{~min}$ and at $50^{\circ} \mathrm{C}$ for $30 \mathrm{~min}$. The reaction was terminated at $85{ }^{\circ} \mathrm{C}$ for 5 min and then chilled on ice. After adding two units of Escherichia coli $\mathrm{RNase} \mathrm{H}$, the reaction was incubated at $37{ }^{\circ} \mathrm{C}$ for $20 \mathrm{~min}$, diluted with DEPC-treated water to a total volume of $100 \mu \mathrm{L}$ (diluted 1:5), and stored at $-20{ }^{\circ} \mathrm{C}$ until further use.

\subsection{Quantitative real-time PCR (qPCR)}

The forward and reverse primers were designed to span at least one intron to prevent false signals caused by genomic DNA contamination. Every hydrolysis probe had two modifications, the fluorophore 6FAM on the 5' end and the quencher BBQ on the 3 ' end. Primer, probe, and amplicon details are listed in the Tables I and II. Each sample was analyzed in triplicate (technical replicate) in a total reaction volume of $25 \mu \mathrm{L}$, containing $0.25 \mu \mathrm{M}$ of each primer, $0.1 \mu \mathrm{M}$ hydrolysis probe, $12.5 \mu \mathrm{L} 2 \times$ Rotor-Gene Multiplex polymerase chain reaction (PCR) Master Mix (Qiagen, Hilden, Germany), and $5 \mu \mathrm{L}$ of the diluted cDNA. Reactions were performed on the real-time PCR cycler Rotor-Gene Q (Qiagen, Hilden, Germany) using the following protocol: $-60^{\circ} \mathrm{C}$ for $1 \mathrm{~min}, 95^{\circ} \mathrm{C}$ for $5 \mathrm{~min}$, and 45 cycles at $95{ }^{\circ} \mathrm{C}$ for $20 \mathrm{~s}$ and $60^{\circ} \mathrm{C}$ for $1 \mathrm{~min}$. The specificity of the PCR products was determined by the sequence specificity of the hydrolysis probe. Quantification cycle $\left(C_{\mathrm{q}}\right)$ values were determined at the same fluorescent threshold (0.1) for each gene. The $C_{\mathrm{q}}$ value for each sample was obtained by calculating the arithmetic mean of the $C_{\mathrm{q}}$ values of each triplicate. The $C_{\mathrm{q}}$ value of each individual was calculated as the mean average of the arithmetic mean $C_{\mathrm{q}} \mathrm{s}$ of the RTPCR duplicates. In addition to the samples, a series of standard concentrations of a PCR product (derived from a plasmid containing the cDNA of the gene) was run for each gene in every qPCR. It was used to
Table I. Sequences of primers and probes used for qPCR assay.

\begin{tabular}{cc}
\hline Gene & Primers and probes $\left(5^{\prime} \rightarrow 3^{\prime}\right)$ \\
\hline rpl32 & Forward: AGTAAATTAAAGAGAAA \\
& CTGGCGTAA \\
& Reverse: TAAAACTTCCAGTTCCTT \\
& GACATTAT \\
& Probe: TGGCAACATATGACGAGTTT \\
& TTTTGT \\
efl $\alpha-f 1$ & Forward: GAACATTTCTGTGAAAG \\
& AGTTGAGG \\
& Reverse: TTTAAAGGTGACACTCTTA \\
& ATGACGC \\
& Probe: ACCGAGGAGAATCCGAAGA \\
GCATCAA \\
Forward: ACCTTCTGCAAAATT \\
ATGGCGA \\
Reverse: CACCTTTGCCAAGTCTA \\
ACTGTTAAG \\
Probe: AGAGCTGGAATAACTTTG \\
CCAACAGCTT
\end{tabular}

calculate the amount of copies in the sample using the standard curve method. Three increasing quantities of DNA $\left(10^{5}\right.$ copies to $10^{7}$ copies per reaction) of the respective gene were used.

PCR efficiency $(E)$ values were calculated by the analysis software Rotor-Gene Q Series Software (version 2.0.2, Qiagen, Hilden, Germany) for each run from the given slope and the following formula $E=10^{-1 / \text { slope }}-1$.

\subsection{Data analysis}

The presence of potential outliers was excluded using the Grubbs test (Grubbs 1969). The expression of the different genes was compared using analysis of variance (ANOVA, IBM SPSS Statistics, Rel. 19.0.0). If variances of the expression data were homogenous, we applied a Scheffé post hoc test $(r p l 32$, gapdh). If they were not homogenous ( $e f l \alpha-$ f1), we used a Tamhane post hoc test.

To calculate the stability of expression for candidate reference genes the software BestKeeper(C) (version 1, Pfaffl et al. 2004), Genorm ${ }^{\text {PLUS }}$ (qbasePLUS, version 2.2, Vandesompele et al. 2002), and NormFinder (version 0.953, Andersen et al. 2004) were used. 
Table II. Description, accession number, amplicon length, and qPCR efficiency with the correlation coefficient $(R)$ of the potential reference genes.

\begin{tabular}{|c|c|c|c|c|}
\hline Symbol & Name & Accession number/Beebase number & Amplicon size & Efficiency $(R)$ \\
\hline rpl32 & Ribosomal protein L32 & $\begin{array}{l}\text { RefSeq: NM_001011587 } \\
\text { Beebase: GB10903 }\end{array}$ & $180 \mathrm{bp}$ & $0.96(0.99)$ \\
\hline$e f 1 \alpha-f 1$ & Elongation factor 1 alpha & $\begin{array}{l}\text { RefSeq: NM_001011628 } \\
\text { Beebase: GB10560 }\end{array}$ & $394 \mathrm{bp}$ & $0.90(0.99)$ \\
\hline gapdh & $\begin{array}{l}\text { Glyceraldehyde 3-phosphate } \\
\text { dehydrogenase }\end{array}$ & $\begin{array}{l}\text { RefSeq: XM_393605 } \\
\text { Beebase: GB14798 }\end{array}$ & $188 \mathrm{bp}$ & $0.92(0.99)$ \\
\hline
\end{tabular}

Genorm $^{\text {PLUS }}$ is a successor of the geNorm Visual Basic Application for Microsoft Excel. These three programs use slightly different algorithms for calculating the gene with the most stable expression.

BestKeeper determines standard deviation and the power of the reference genes on which the most stably expressed gene is selected. NormFinder determines a stability value based on the overall variation and the variation between sample subgroups of the candidate reference genes and selects the gene with the least expression variation as the most stably expressed reference gene. It is a direct measure of the estimated variation in expression. Genorm ${ }^{\text {PLUS }}$ automatically calculates relative quantities from the $C_{\mathrm{q}}$ values. Afterward, the program determines the gene-stability value $M$, defined as average pair-wise variation between a particular gene and all other control genes in a given set of samples. The gene with the highest $M$ value is the least stably expressed gene and was eliminated before the remaining genes were calculated again. The reference gene with the lowest $M$ value has the most stable expression. In addition, the genespecific variation in each control gene was determined after normalization as the coefficient of variation (CV) of expression levels. The CV should be minimal for the most stably expressed reference gene.

\section{RESULTS}

\subsection{Age-dependent variation in gene expression}

Each reference gene shows age-dependent changes in mRNA expression (efl $\alpha-f 1: F=$ $3.025, P=0.027$; rpl32: $F=8.163, P \leq 0.001$; gapdh: $F=6.046, P \leq 0.001$, one-way ANOVA). The expression of efl $\alpha-f 1$ mRNA was significantly stronger in the brains of newly emerged bees compared with those of 6-day-old bees $(P=0.03$, Tamhane test) but did not differ between 12-day-old bees, pollen foragers, or nectar foragers (Figure 1A). Rpl32 expression was significantly stronger in the brains of 12 day-old bees compared with those of newly emerged bees, 6-day-old bees, and pollen foragers (Figure 1B; 12 versus 0 days: $P \leq$ $0.001 ; 12$ versus 6 days: $P=0.019 ; 12$ days versus pollen foragers: $P=0.035$, Scheffé test). Nectar foragers differed in expression only from newly emerged bees (nectar foragers versus 0 days: $P=0.01$, Scheffé test). The other groups were intermediate. The expression of gapdh mRNA was significantly stronger in the brains of newly emerged bees compared with those of most age groups apart from nectar foragers (Figure $1 \mathrm{C} ; P \leq 0.05$, Scheffé test).

\subsection{Test for stability of expression}

Analysis with the software Bestkeeper revealed that the mRNA expression level of none of the tested reference genes has a standard deviation (SD) greater than 1 , so that all of the tested genes can be used for qPCR normalization. All genes show a significant correlation to the Bestkeeper index $(P \leq 0.001)$. Based on the SD of the value of the cycle number used for quantification $\left(C_{\mathrm{q}}\right)$, gapdh 


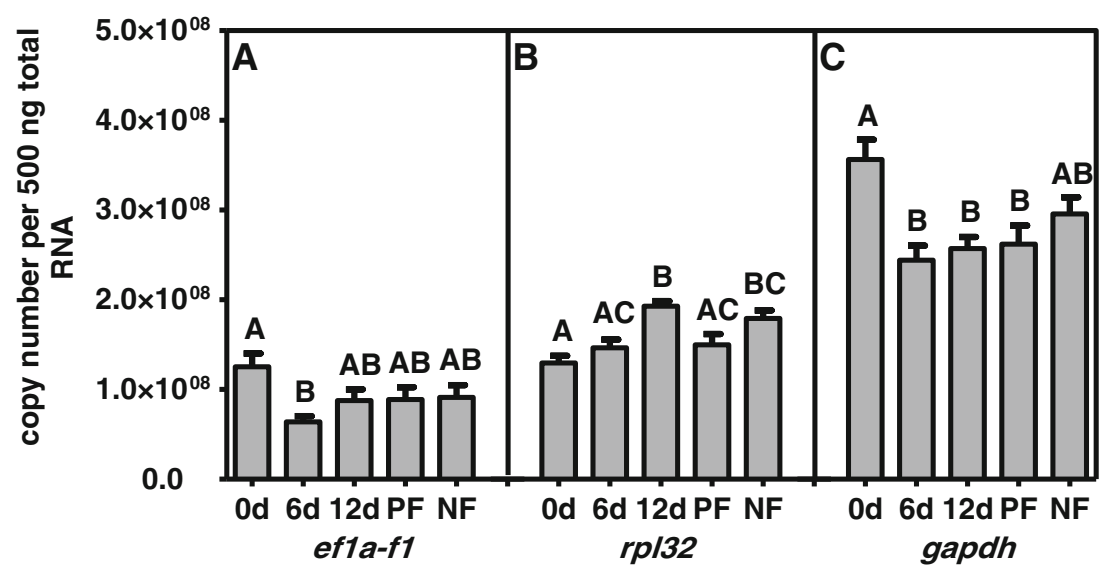

Figure 1. Expression levels of efl $\alpha-f 1-$, rpl32-, and gapdh-mRNA in the whole brain of worker bees. Brain expression of all three genes was age-dependent $(P \leq 0.001$, ANOVA). Bars indicate mean copy number \pm standard error. Different letters indicate significantly different groups $(P \leq 0.05$, Tamhane or Scheffé Tests, see text). Ages: newly emerged ( 0 days), 6-day-old bees (6 days), 12-day-old bees (12 days), pollen foragers $(P F)$, nectar foragers $(N F)$. Number per age group: ten.

could be ranked as the most reliable reference gene, followed by rpl32 and efl $\alpha-f 1$ (Table III).

Genorm $^{\text {PLUS }}$ also identified gapdh as most stably expressed gene (stability value $M=0.464$, $\mathrm{CV}=0.133) . R p l 32(M=0.576, \mathrm{CV}=0.240)$ and efl $\alpha$-f1 $(M=0.607, C V=0.276)$ came second and third, respectively (Figure 2). All of the Genorm $^{\text {PLUS }}$ tested reference genes have an $M$ value below 1.5 and are therefore expressed stably enough to be used as reference genes in qPCR.

In whole-brain homogenates, NormFinder ranked gapdh as the most stably expressed reference gene (stability value 0.102 ), followed by $r p l 32(0.197)$ and efl $\alpha-f l(0.223)$ (Figure 3). When two reference genes are used, the best combination is gapdh and rpl32 (0.120).

\section{DISCUSSION}

\subsection{Comparison of expression stability between genes}

For reliable results in qPCR studies, a precise normalization of gene expression levels is an absolute prerequisite (Vandesompele et al. 2002). The ideal internal standard should be expressed at a constant level among different tissues of an organism at all stages of development and should be unaffected by the experimental treatment (Bustin 2000). Unfortunately, no study has yet identified a single reference gene that is suitable across all developmental stages within an organism (Bagnall and Kotze 2010). In studies on gene expression in A. mellifera, the most frequently used reference genes have been rpl32 (former rp49) (Ben-Shahar et al. 2003;

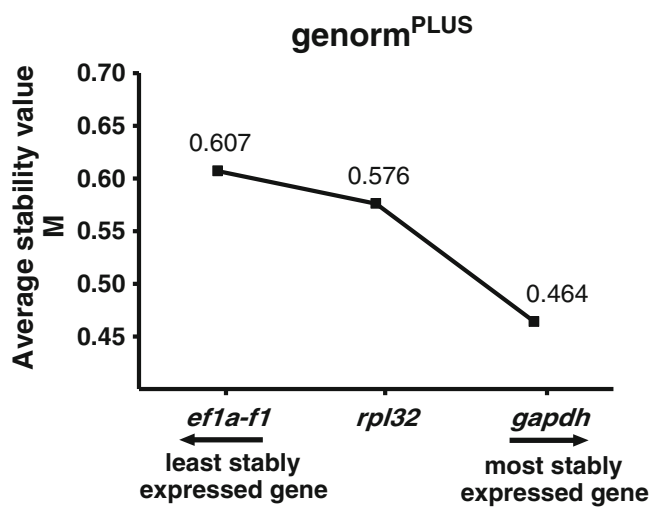

Figure 2. Gene expression stability values $M$ of the three candidate reference genes in adult honey bee brain. Values were determined by the Genorm ${ }^{\text {PLUS }}$ software and plotted from least stable one (left) to most stable one (right). 


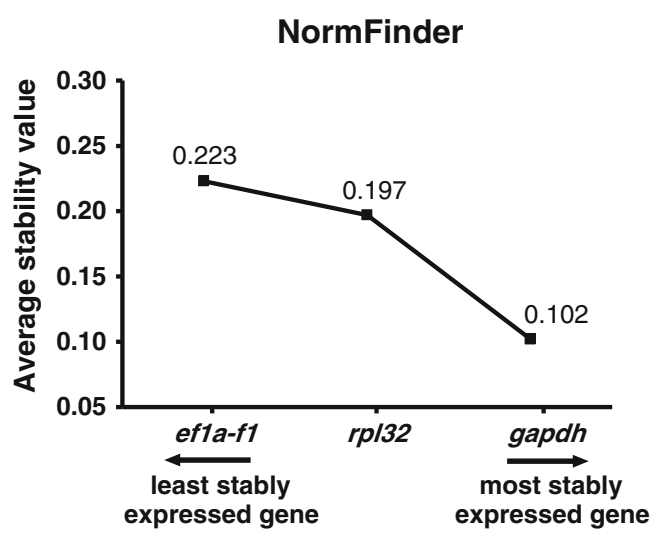

Figure 3. Gene expression stability values of the candidate reference genes in adult honey bee brain. Values were determined by the NormFinder software and plotted from the least stably expressed one (left) to most stably expressed one (right).

Grozinger et al. 2003; Corona et al. 2007; Ament et al. 2008; Navajas et al. 2008) and efl $\alpha-f 1$ (Toma et al. 2000; Bloch et al. 2001; Yamazaki et al. 2006), but whether expression of these genes remains stable throughout adult development was not yet tested in detail.

We analyzed the stability of expression for these two reference genes and for gapdh, another typical reference gene, in the brain of honey bee workers over the entire adulthood. Honey bees show an age-dependent division of labor which is often studied with respect to changes in gene expression (Bloch et al. 2001; Ben-Shahar et al. 2003; Ament et al. 2008). These studies require

Table III. Descriptive statistics and regression analysis of BestKeeper versus reference gene.

\begin{tabular}{lrrr}
\hline & efl $\alpha-f 1$ & rpl32 & gapdh \\
\hline$N$ & \multicolumn{1}{l}{50} & \multicolumn{1}{l}{50} & \multicolumn{1}{l}{50} \\
Geometric mean $\left(C_{\mathrm{q}}\right)$ & 22.63 & 22.33 & 20.16 \\
$\begin{array}{l}\text { Standard deviation } \\
\left( \pm C_{\mathrm{q}}\right)\end{array}$ & 0.55 & 0.30 & 0.28 \\
$\begin{array}{l}\text { Coefficient of } \\
\text { determination }\left(r^{2}\right)\end{array}$ & 0.76 & 0.25 & 0.74 \\
$p$ value & 0.001 & 0.001 & 0.001 \\
\hline
\end{tabular}

reliable reference genes with stable expression across the observed age groups.

In our study, none of the three analyzed genes was expressed constantly during adult development. Both efl $\alpha-f 1$ and gapdh were expressed at a constant level in the brains of bees older than 6 days but were expressed at significantly higher levels in the brains of newly emerged bees. Expression of rpl32 mRNA differed between newly emerged bees and 12day-old bees. This may partly be explained by the fact that protein products of the reference genes are not only implicated in the basal cell metabolism but also participate in other functions (for review, see Sirover 1997). Therefore, the question arises whether it is possible at all to find a gene which does not change its expression level during adult development or under different conditions.

Although the expression of all three reference genes tested in the brain differed within adult honey bees, we could rank the genes according to their expression stability. The three programs NormFinder, Bestkeeper, and Genorm ${ }^{\text {PLUS }}$ ranked gapdh as the most stably expressed reference gene, followed by rpl32 and efl $\alpha-f 1$. Some authors recommend using at least two reference genes (Vandesompele et al. 2002). According to NormFinder, gapdh and rpl32 should be used for adult honey bee brains. But, it is also acceptable to use only one reference gene as an internal control if it is expressed stably under the same experimental conditions (Thellin et al. 1999; Bustin et al. 2009).

Gapdh is a metabolic enzyme that takes part in a great variety of processes (Sirover 1997). Our validation of gapdh as the most stably expressed reference gene corresponds well with the findings of Scharlaken et al. (2008) for honey bees after bacterial infection and for the desert locust (Van Hiel et al. 2009). Surprisingly, none of the gene expression studies performed in honey bees used gapdh for normalization, although it is one of the most frequently used reference genes in the history of qPCR (for review, see Suzuki 2000). This is possibly related to the fact that gapdh is one of the most unstably expressed reference genes in 
other insects (Bagnall and Kotze 2010; Hornáková et al. 2010; Chapuis et al. 2011).

Although the expression of rpl32 and efl $\alpha-f 1$ is not as stable as that of gapdh, the former two genes are expressed stably enough to be used as reference genes in studies on adult honey bee brains, supporting results of McQuillan et al. (2012). Interestingly, rpl32, which is part of the $60 \mathrm{~S}$ ribosomal subunit, is even the most stably expressed gene in the pre-adult development of honey bee workers (Lourenco et al. 2008, under the former name of rp49) and in the brains from fifth-instar larvae of the desert locust (Van Hiel et al. 2009). Efl $\alpha-f l$ takes part in the translational process and is the least stably expressed gene in our study, although it was identified as one of the most stably expressed reference genes in adult locusts (Van Hiel et al. 2009; Chapuis et al. 2011), bumble bees (Hornáková et al. 2010), and fruit flies (Ponton et al. 2011).

\subsection{Gene expression and experimental condition}

The choice of a suitable reference gene depends mainly on the experimental situation. For example, in a study by Thellin et al. (1999), the amounts of gapdh did not vary between different rat subspecies and between different nervous tissues but varied highly in human mononuclear blood cells after the addition of different activators like ionomycin. Also, the stability of $r p l 32$ and efl $\alpha-f l$ mRNA expression varies with the experimental design. Although rpl32 is expressed stably during development of honey bee larvae and pupae, its expression becomes very unstable when bees are treated with juvenile hormone (Lourenco et al. 2008). Similar variations were observed for ef $1 \alpha-f 1$ (Lourenco et al. 2008). These results show that, even if gene expression is stable under normal conditions, expression of the same genes may become instable after treatment with chemicals.

\subsection{Recommendation}

For gene expression studies on brains of adult honey bees older than 1 day old, we suggest gapdh should be given preference as reference gene. When gene expression is studied in young hive bees, $r p l 32$ is the best choice, in our opinion. Generally, we recommend using all three programs (Bestkeeper, Genorm ${ }^{\text {PLUS }}$, and NormFinder) to validate expression of reference genes for each new experimental situation.

\section{ACKNOWLEDGMENTS}

The authors thank Benedikt Polaczek for assistance in beekeeping. This work was supported by grants from the German Research Foundation (DFG) to RS (SCH1573/2-1, SCH1573/4-1) and WB (BL469/7-1).

Possibilité d'utiliser trois gènes de référence communs pour une PCR quantitative en temps réel chez les abeilles

Expression génique / PCR quantitative / gène de référence / programme de stabilité / Apis mellifera

Untersuchung von drei häufig verwendeten Referenzgenen für quantitative Echtzeit-PCR in Honigbienen

Genexpression / quantitative PCR / Referenzgene / Stabilitätsprogramme / Apis mellifera

\section{REFERENCES}

Ament, S.A., Corona, M., Pollock, H.S., Robinson, G.E. (2008) Insulin signaling is involved in the regulation of worker division of labor in honey bee colonies. Proc. Natl. Acad. Sci. U. S. A. 105, 4226-4231

Andersen, C.L., Jensen, J.L., Ørntoft, T.F. (2004) Normalization of real-time quantitative reverse transcription-PCR data: a model-based variance estimation approach to identify genes suited for normalization, applied to bladder and colon cancer data sets. Cancer Res. 64, 5245-5250

Bagnall, N.H., Kotze, A.C. (2010) Evaluation of reference genes for real-time PCR quantification of gene expression in the Australian sheep blowfly, Lucilia cuprina. Med. Vet. Entomol. 24, 176-181

Ben-Shahar, Y., Leung, H.T., Pak, W.L., Sokolowski, M.B., Robinson, G.E. (2003) cGMP-dependent changes in phototaxis: a possible role for the 
foraging gene in honey bee division of labor. J. Exp. Biol. 206, 2507-2515

Bloch, G., Toma, D.P., Robinson, G.E. (2001) Behavioral rhythmicity, age, division of labor and period expression in the honey bee brain. J. Biol. Rhythms. 16, 444-456

Bustin, S.A. (2000) Absolute quantification of mRNA using real-time reverse transcription polymerase chain reaction assays. J. Mol. Endocrinol. 25, 169193

Bustin, S.A., Nolan, T. (2004) Pitfalls of quantitative real-time reverse-transcription polymerase chain reaction. J. Biomol. Tech. 15, 155-166

Bustin, S.A., Benes, V., Garson, J.A., Hellemans, J., Huggett, J., Kubista, M., Mueller, R., Nolan, T., Pfaffl, M.W., Shipley, G.L., Vandesompele, J., Wittwer, C.T. (2009) The MIQE guidelines: minimum information for publication of quantitative real-time PCR experiments. Clin. Chem. 55, 611622

Chapuis, M.P., Tohidi-Esfahani, D., Dodgson, T., Blondin, L., Ponton, F., Cullen, D., Simpson, S.J., Sword, G.A. (2011) Assessment and validation of a suite of reverse transcription-quantitative PCR reference genes for analyses of density-dependent behavioural plasticity in the Australian plague locust. BMC Mol. Biol. 12, 7

Corona, M., Velarde, R.A., Remolina, S., Moran-Lauter, A., Wang, Y., Hughes, K.A., Robinson, G.E. (2007) Vitellogenin, juvenile hormone, insulin signaling, and queen honey bee longevity. Proc. Natl. Acad. Sci. U. S. A. 104, 7128-7133

Danforth, B.N., Shuqing, J. (1998) Elongation Factor-1 $\alpha$ occurs as two copies in bees: implications for phylogenetic analysis of EF-1 $\alpha$ sequences in insects. Mol. Biol. Evol. 15(3), 225-235

Grozinger, C.M., Sharabash, N.M., Whitfield, C.W., Robinson, G.E. (2003) Pheromone-mediated gene expression in the honey bee brain. Proc. Natl. Acad. Sci. U. S. A. 100(Suppl 2), 14519-14525

Grubbs, F.E. (1969) Procedures for detecting outlying observations in samples. Technometrics 11, 1-21

Hornáková, D., Matousková, P., Kindl, J., Valterová, I., Pichová, I. (2010) Selection of reference genes for real-time polymerase chain reaction analysis in tissues from Bombus terrestris and Bombus lucorum of different ages. Anal. Biochem. 397, $118-120$

Huggett, J., Dheda, K., Bustin, S., Zumla, A. (2005) Real-time RT-PCR normalisation; strategies and considerations. Genes. Immun. 6, 279-284

Kubista, M., Andrade, J.M., Bengtsson, M., Forootan, A., Jonák, J., Lind, K., Sindelka, R., Sjöback, R., Sjögreen, B., Strömbom, L., Ståhlberg, A., Zoric, N. (2006) The real-time polymerase chain reaction. Mol. Aspects Med. 27, 95-125

Ling, D., Salvaterra, P.M. (2011) Robust RT-qPCR data normalization: validation and selection of internal reference genes during post-experimental data analysis. PLoS One 6(3), e17762

Lord, J.C., Hartzer, K., Toutges, M., Oppert, B. (2010) Evaluation of quantitative PCR reference genes for gene expression studies in Tribolium castaneum after fungal challenge. J. Microbiol. Methods 80, 219-221

Lourenco, A.P., Mackert, A., Cristino, A.S., Simoes, Z.L.P. (2008) Validation of reference genes for gene expression studies in the honey bee, Apis mellifera, by quantitative real-time RT-PCR. Apidologie 39, 372-385

Majerowicz, D., Alves-Bezerra, M., Logullo, R., Fonseca-de-Souza, A.L., Meyer-Fernandes, J.R., Braz, G.R., Gondim, K.C. (2011) Looking for reference genes for real-time quantitative PCR experiments in Rhodnius prolixus (Hemiptera: Reduviidae). Insect Mol. Biol. 20, 713-722

Mamidala, P., Rajarapu, S.P., Jones, S.C., Mittapalli, O. (2011) Identification and validation of reference genes for quantitative real-time polymerase chain reaction in Cimex lectularius. J. Med. Entomol. 48, 947-951

McQuillan, H.J., Nakagawa, S., Mercer, A.R. (2012) Mushroom bodies of the honeybee brain show cell population-specific plasticity in expression of amine-receptor genes. Learn. Mem. 19, 151-158

Mustard, J.A., Blenau, W., Hamilton, I.S., Ward, V.K., Ebert, P.R., Mercer, A.R. (2003) Analysis of two D1-like dopamine receptors from the honey bee Apis mellifera reveals agonist-independent activity. Brain Res. Mol. Brain. Res. 113, 67-77

Navajas, M., Migeon, A., Alaux, C., Martin-Magniette, M., Robinson, G.E., Evans, J., Cros-Arteil, S., Crauser, D., Le Conte, Y. (2008) Differential gene expression of the honey bee Apis mellifera associated with Varroa destructor infection. BMC Genomics 9, 301-301

Pfaffl, M.W. (2001) A new mathematical model for relative quantification in real-time RT-PCR. Nucleic Acids Res. 29(9), e45

Pfaffl, M.W., Tichopad, A., Prgomet, C., Neuvians, T.P. (2004) Determination of stable housekeeping genes, differentially regulated target genes and sample integrity: Bestkeeper-Excel-based tool using pair-wise correlations. Biotechnol. Lett. 26, 509-515

Ponton, F., Chapuis, M.P., Pernice, M., Sword, G.A., Simpson, S.J. (2011) Evaluation of potential reference genes for reverse transcription-qPCR studies of physiological responses in Drosophila melanogaster. J. Insect. Physiol. 57, 840-850

Scharlaken, B., de Graaf, D.C., Goossens, K., Brunain, M., Peelman, L.J., Jacobs, F. (2008) Reference gene selection for insect expression studies using quantitative real-time PCR: the head of the honeybee, Apis mellifera, after a bacterial challenge. J. Insect. Sci. 8, 1-10

Sirover, M.A. (1997) Role of the glycolytic protein, glyceraldehyde-3-phosphate dehydrogenase, in nor- 
mal cell function and in cell pathology. J. Cell. Biochem. 66, 133-140

Suzuki, T., Higgins, P.J., Crawford, D.R. (2000) Control selection for RNA quantitation. Biotechniques 29, 332-337

Thellin, O., Zorzi, W., Lakaye, B., De Borman, B., Coumans, B., Hennen, G., Grisar, T., Igout, A., Heinen, E. (1999) Housekeeping genes as internal standards: use and limits. J. Biotechnol. 75, 291-295

Toma, D.P., Bloch, G., Moore, D., Robinson, G.E. (2000) Changes in period mRNA levels in the brain and division of labor in honey bee colonies. Proc. Natl. Acad. Sci. U. S. A. 97, 6914-6919

Van Hiel, M.B., Van Wielendaele, P., Temmerman, L., Van Soest, S., Vuerinckx, K., Huybrechts, R., Broeck, J.V., Simonet, G. (2009) Identification and validation of housekeeping genes in brains of the desert locust Schistocerca gregaria under different developmental conditions. BMC Mol. Biol. 10, 56-56
Vandesompele, J., De Preter, K., Pattyn, F., Poppe, B., Van Roy, N., De Paepe, A., Speleman, F. (2002) Accurate normalization of real-time quantitative RTPCR data by geometric averaging of multiple internal control genes. Genome Biol. 3(7), RESEARCH0034

Walldorf, U., Hovemann, B.T. (1990) Apis mellifera cytoplasmic elongation factor 1 alpha $(\mathrm{EF}-1 \alpha)$ is closely related to Drosophila melanogaster EF-1 $\alpha$. FEBS Lett. 267(2), 245-249

Winnebeck, E.C., Millar, C.D., Warman, G.R. (2010) Why does insect RNA look degraded? J. Insect. Sci. 10, $159-159$

Yamazaki, Y., Shirai, K., Paul, R.K., Fujiyuki, T., Wakamoto, A., Takeuchi, H., Kubo, T. (2006) Differential expression of HR38 in the mushroom bodies of the honeybee brain depends on the caste and division of labor. FEBS Lett. 580, 2667-2670 